OPEN ACCESS

Edited by:

Betul Buyuktiryaki,

Koç University Hospital, Turkey

Reviewed by:

Mustafa Arga,

Istanbul Medeniyet University, Turkey Jorge Amil Dias,

Centro Hospitalar de São João,

Portugal

*Correspondence:

Amelia Lican

a.licari@smatteo.pv.it

Specialty section:

This article was submitted to

Pediatric Immunology,

a section of the journal

Frontiers in Pediatrics

Received: 22 November 2021 Accepted: 27 December 2021

Published: 20 January 2022

Citation:

Votto M, De Filippo M, Lenti MV Rossi CM, Di Sabatino A,

Marseglia GL and Licari A (2022) Diet Therapy in Eosinophilic Esophagitis. Focus on a Personalized Approach.

Front. Pediatr. 9:820192.

doi: 10.3389/fped.2021.820192

\section{Diet Therapy in Eosinophilic Esophagitis. Focus on a Personalized Approach}

\author{
Martina Votto ${ }^{1}$, Maria De Filippo ${ }^{1}$, Marco Vincenzo Lenti ${ }^{2}$, Carlo Maria Rossi ${ }^{2}$, \\ Antonio Di Sabatino ${ }^{2}$, Gian Luigi Marseglia ${ }^{1,3}$ and Amelia Licari ${ }^{1,3 *}$ \\ ${ }^{1}$ Department of Clinical, Surgical, Diagnostic and Pediatric Sciences, University of Pavia, Pavia, Italy, ${ }^{2}$ Department of Internal \\ Medicine, Fondazione IRCCS Policlinico San Matteo, University of Pavia, Pavia, Italy, ${ }^{3}$ Pediatric Clinic, Fondazione IRCCS \\ Policlinico San Matteo, Pavia, Italy
}

Eosinophilic esophagitis (EoE) is a chronic allergic disease defined by a marked eosinophilic inflammation and symptoms of esophageal dysfunction. EoE is a heterogeneous disease and severely impacts the quality of life of affected patients. The current therapeutic management of EoE is based on two cornerstones: medication and diet therapy, both effective but limited by several critical issues. The choice of one or the other therapy might depend on the different disease phenotypes (allergic vs. non-allergic, inflammatory vs. fibro-stenotic), patient's age (adult vs. childhood-onset), food habits, patient/family preference, and familiar financial resource. Diet therapy is a successful treatment but limited by low patient adherence, the need for several endoscopies, food restrictions, psychosocial impact, and potential nutritional deficiencies. All these limitations could be effectively overcome with multidisciplinary and personalized management. This review summarizes the most recent evidence on the dietary elimination approaches and will provide a practical guide to clinicians in managing and implementing dietary therapy for patients with EoE.

\footnotetext{
Keywords: eosinophilic esophagitis, diet, food allergens, food-reintroduction, personalized therapy, multidisciplinary approach, phenotype, endotype
}

\section{INTRODUCTION}

Eosinophilic esophagitis (EoE) is the most characterized eosinophilic gastrointestinal disorder (EGID) and is a chronic/remittent allergic disease, defined by a marked eosinophilic inflammation and symptoms of esophageal dysfunction $(1,2)$. Currently, the diagnosis of EoE requires the presence of more than 15 eosinophils per high power field (eos/HPF) in the endoscopically obtained esophageal biopsies in patients with suspicious symptoms $(1,2)$.

It is estimated that EoE affects about $0.5-1 / 1,000$ patients in the USA, varying widely across the different Countries and mostly prevailing in Caucasian patients and male sex (3). However, in the last 20 years, several epidemiological studies showed a significant increase in the epidemiology of EGIDs, partially related to improved medical awareness and knowledge through modern diagnostic instruments (4-6). It was also postulated that changes in environmental factors may have contributed to the significant increase in EoE epidemiology (7). Recently, Navarro et al. found that the pooled prevalence of EoE is 34.4 cases/100,000 inhabitants and is higher for adults than for children $(42.2 / 100,000$ vs. $34 / 100,000)(5)$. The pooled incidence rate was $6.6 / 100,000$ people per year in children and 7.7/100,000 in adults (5). 
Genome-wide association studies have identified multiple susceptibility genes associated with EoE risk and a complex model of disease inheritance. EoE is a multifactorial disease typically characterized by a type 2 (T2) inflammation (8). The impaired epithelial barrier function plays a pivotal role in the pathophysiology of EoE, inducing the release of alarmins (thymic stromal lymphopoietin, IL-15, IL-33), which then activates the type 2 innate lymphoid cells (ILC2) and basophils. The subsequent release of IL-4, IL-5, and IL-13 recruits and expands the eosinophilic inflammation. The consequences of this sustained inflammation include tissue remodeling and esophageal dysfunction. Esophageal fibrosis begins in the early phases of the disease course, initially involving the lamina propria (6). Fibrosis has been found in $57-88 \%$ of young patients and children and $89 \%$ of adult patients with EoE (9). However, the increased esophageal stiffness, due to subepithelial fibrosis and muscular hypertrophy, clinically occurs with food impaction and dysphagia, symptoms that are typically reported by adult patients (Figure 1) (9). Although the pathogenesis is not entirely understood and is likely non-IgE-mediated, food allergens are known to trigger EoE, stimulating the already dysregulated immune cells through the impaired esophageal epithelial barrier $(10,11)$. Most patients with EoE are allergic to $1-3$ foods that trigger esophageal inflammation, according to Koch's postulate (12). Esophageal inflammation is resolved once the food(s) is removed from the diet, and reproducibility reactivates it when the culprit allergen(s) is reintroduced (10,12-14). Recent and conflicting studies have also supported the potential role of aeroallergens in the pathogenesis of EoE, with evidence mostly limited to case series and case reports $(8,15)$.

Since EoE was first recognized as a distinct clinical entity in the mid-1990's, several signs of progress were achieved. However, there are diagnostic and therapeutic aspects that should be investigated, and one of these concerns the diet therapy and nutritional assessment of patients with EoE. To date, most data on nutritional management came from the single center's experience rather than comparative clinical trials. This review summarizes the most recent evidence on the dietary elimination approaches and will provide a practical guide to clinicians in managing and implementing dietary therapy for patients with EoE.

\section{CLINICAL FEATURES AND HETEROGENEITY OF EOE}

EoE is a heterogeneous disease with variable symptoms and severity, comorbidities (atopic vs. non-atopic), treatment response, and natural history. Moreover, EoE severely impacts both adults and children's quality of life (QoL) (16, 17). Notably, EoE symptoms vary with age (1). Toddler and young children generally experienced food refusal, feeding difficulties, and recurrent vomiting and/or regurgitation. On the contrary, school-aged children reported abdominal/epigastric pain, refractory gastroesophageal reflux, whereas adolescents and adults present dysphagia and food impaction. Symptoms, endoscopic and histological findings, and response to treatments reflect the typical evolution of the EoE inflammation through time, as reported in Figure 1. In this context, different clinical patterns or phenotypes have been identified (16). The "inflammatory" pattern is generally observed in childhood and is defined by the endoscopic evidence of edema, erythema, linear furrowing, and the prevalent eosinophilic esophageal inflammation in histologic samples $(16,18,19)$. On the other hand, the "fibro-stenotic" and "fibrotic" phenotypes primarily affect adolescents and adults with dysphagia and food impaction $(16,18-20)$. These phenotypes are endoscopically characterized by fixed esophageal rings and/or strictures resulting from tissue remodeling and esophageal fibrosis (16, 18-20). The clinical and histological heterogeneity might reflect and partially explain the heterogeneous response to available therapies (16). While diet and medical therapies may reduce tissue fibrosis in childhood, this remodeling process may persist despite the resolution of inflammation in adulthood (6). Recently, Shoda et al. identified three potential endotypes of EoE, using a machine learning approach to analyze histological, endoscopic, and molecular features of US patients with EoE. The first endotype (EoEe1) was recognized in $35 \%$ of the cohort and was mainly characterized by a minimal eosinophilic inflammation and steroid responsiveness. The EoEe2 endotype affected 29\% of patients and showed a prevalent $\mathrm{T} 2$ inflammation, pediatric-onset, and a low steroid response. Finally, 36\% of the EoE cohort (EoEe3) presented an adult-onset and structuring disease $(16,21)$. Therefore, according to this endotype classification, patients with the EoEel endotype might successfully be treated with diet and steroid therapy, and children with the EoEe2 endotype might benefit from the anti-T2 immune agents (i.e., dupilumab) (22). Finally, adult patients with the EoEe3 endotype are more challenging to treat with available therapies; thus, esophageal dilatations are the only current solution to esophageal stenosis (22). In the future, a validated endo-phenotype classification of EoE will provide better disease management and aim physicians to develop a personalized medicine using targeted treatments.

\section{HOW TO MANAGE EOE}

The current therapeutic management of EoE is based on two cornerstones: the medication (proton pump inhibitors [PPIs] and topical corticosteroids) and diet therapy, both effective but limited by different critical issues $(2,17,18)$. Patients with EoE should be maintained on monotherapy when effective $(2,23)$. However, if monotherapy fails or loses its efficacy, a combination therapy (diet + topical steroid) may be indicated (24). Although not already approved, biological therapy with dupilumab showed promising results in adults with EoE, improving symptoms, esophageal inflammation, and distensibility (25).

When correctly administered (1 $\mathrm{mg} / \mathrm{kg} /$ day, twice daily), PPIs are effective in about $50 \%$ of children with EoE. The long-term effectiveness of PPIs is still debated and might be related to specific genetic polymorphisms $(26,27)$. However, disease remission might appear more sustained in patients with the inflammatory phenotype than those with the fibrostenotic or stenotic phenotype $(19,26,27)$. Therefore, as widely 


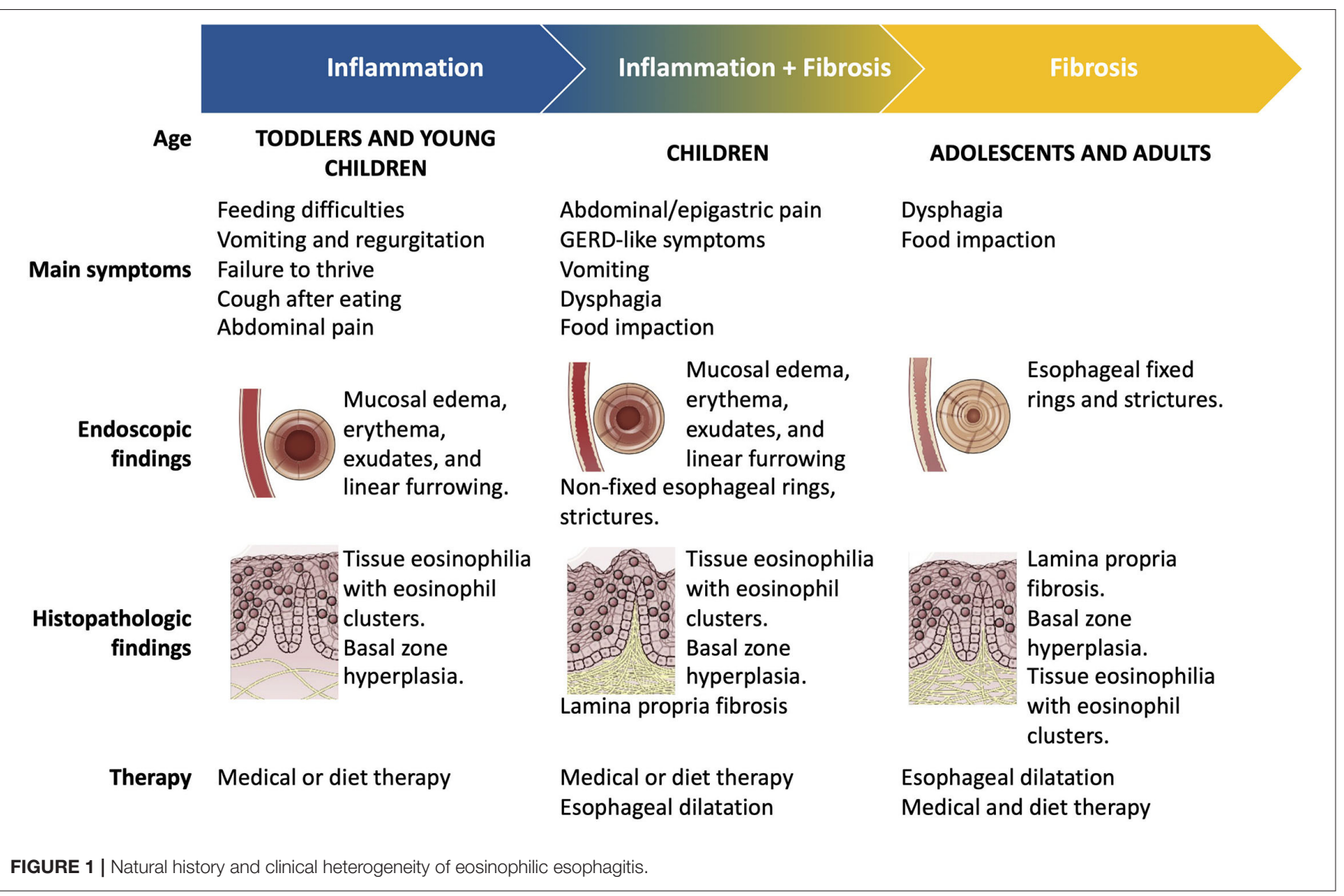

reported, PPI response is not homogeneous and prolonged in all patients (27).

Current formulations of topical corticosteroids have not yet been approved by the Food and Drug Administration (FDA) (27). However, in 2017, the European Medicines Agency (EMA) authorized orodispersible budesonide for adults with EoE (https://www.ema.europa.eu/en/documents/assessmentreport/jorveza-epar-public-assessment-report_en.pdf). Slurry budesonide and swallowed fluticasone are both effective to induce EoE remission. However, their long-term use is compromised by patient adherence and side effects $(19,27)$. Although topical corticosteroids are generally safe and welltolerated, long-term administration is complicated mainly by esophageal candidiasis in $1-3 \%$ of patients $(19,27)$. Moreover, there have been sporadic reports of decreased cortisol levels, minor anthropometric growth changes, and low bone mineral density; thus, physicians may consider periodic monitoring for growth, adrenal, and bone metabolism (27). When complete remission is achieved, topical corticosteroid treatment should be administered at the minimal effective dosage to reduce the risk of potential long-term side effects. On the other hand, a brief cycle of oral/systemic corticosteroid is also suggested for controlling refractory esophageal inflammation (28).

In 1995, Kelly et al. successfully demonstrated the efficacy of the exclusive aminoacid-based formula diet in children with EoE (29). Since this attempt, several studies have evaluated
TABLE 1 | Diet therapies of eosinophilic esophagitis.

\begin{tabular}{lll}
\hline Diets & $\begin{array}{l}\text { Specific } \\
\text { recommendation }\end{array}$ & Results \\
\hline Elemental diet & Elemental formula & $\begin{array}{l}\text { Adults and } \\
\text { children } \sim 90 \%\end{array}$ \\
Elimination diet & Cow's milk, wheat, & Adults 52-70\% \\
6-food & eggs, soy/legumes, & Children $74 \%$ \\
& seafood, nuts & Adults $52-70 \%$ \\
4-food & Cow's milk, wheat, & Children $74 \%$ \\
2-food & eggs, soy/legumes & Adults and children \\
& Cow's milk, wheat & $43 \%$ \\
1-food & Cow's milk & Adults and children \\
& & $44-70 \%$
\end{tabular}

IgE, immunoglobulin E.

the therapeutic role of elimination diets. Three main dietary approaches, such as the elemental, empiric, and allergy testdirected elimination diets, have been proposed with variable efficacy rates and specific advantages and disadvantages (Table 1) $(2,28)$. Although the therapeutic choice mainly depends on clinician experience and patient's needs, several clinical aspects must be considered before prescribing a diet therapy, especially in children. 


\section{DIET THERAPY}

\section{What Clinicians Should Know Before Prescribing a Diet Therapy}

According to international guidelines, the diet approach is considered the first-line treatment of EoE and is as effective as medication therapy $(2,28)$. It is widely demonstrated that foods are the primary triggers of EoE; indeed, food elimination diets (FEDs) have demonstrated complete remission of EoE, with higher rates $(>90 \%)$ in patients treated with elemental diet than empirical FEDs and test directed diets (12). However, FEDs are challenging and are not risk-free. Patients on diet therapy may potentially develop nutritional deficiencies, eating disorders and experience a low QoL and high psychological impacts. Before prescribing a FED, allergists and gastroenterologists should consider several clinical aspects, such as (1) disease-severity and patient's nutritional status, (2) presence of maladaptive feeding behaviors or/and food allergies, (3) family and patient preferences, and (4) financial resources (27). Then, clinicians should widely explain to patients and their families the advantages and disadvantages of diets to choose judiciously (7, 27). Children and adults, candidates for diet therapy, should also be informed of the need to undergo several endoscopic and clinical evaluations to confirm or assess disease remission $(2,28)$. Patients and parents of children with EoE should know that more restrictive diet therapies (elemental and empirical FED) may be expensive and alternative foods may be often found only in specialty stores (30). On the other hand, clinicians should guarantee a strict follow-up with upper GI endoscopy to evaluate the remission 6-12 weeks after diet beginning and each food reintroduction $(2,28)$. Moreover, physicians should consider patients' food habits, such as eating at home/work or school canteen, reliance on pre-prepared foods, and cultural issues (12).

At baseline, patients with active EoE are generally not malnourished (31). However, toddlers and young children may present growth failure and feeding issues that are not a contraindication for an elimination diet after a comprehensive assessment of the nutritional status (32). As reported in different pediatric studies, a significant proportion of children with EoE has other coexisting allergic diseases, including multiple IgEmediated food allergies (33-35). These patients generally are not the best candidates for FEDs, as the extensive food restrictions may compromise patient's compliance and negatively impact on QoL (14).

\section{Elemental Diet}

The elemental diet consists in removing all foods. Thus, patients are exclusively fed with an aminoacid-based formula for at least 6 weeks $(2,28,36)$. The elemental diet is the most effective treatment, and several studies reported high complete remission rates in children and adults with active EoE (37). EoE patients treated with the elemental diet experienced a significant reduction in their symptoms and achieved complete histologic remission in 90 and $94 \%$ of pediatric and adult cases, respectively (Table 1). Moreover, the highest efficacy rates are primarily observed in patients with a non-stricturing phenotype (27, 38-41).
TABLE 2 | Advantages and disadvantages of elemental diet.

\begin{tabular}{ll}
\hline Advantages & Disadvantages \\
\hline - Rapid and complete remission & - Poor palatability and low \\
in 2 weeks & patient's compliance \\
- Better acceptance in young & - The administration through NG \\
children and toddlers & or G-tube may induce feeding \\
- Rescue therapy or temporary & skills regression \\
solution in adults with & - High cost and insurance \\
non-stricturing EoE & coverage \\
- Pediatric formulas are almost & - Less effective in stricturing EoE \\
nutritionally complete & \\
- Nutritional supplement &
\end{tabular}

EoE, eosinophilic esophagitis; G, gastric; NG, nasal gastric.

The elemental diet is a fundamental therapeutic option, especially in severe EoE cases. However, the elemental diet is not the first-line approach for its limitations in most cases (12). Elemental diet is often proposed as rescue therapy or temporary solution in adults and adolescents with refractory EoE when all other treatments alone or in combination have failed $(12,27)$. In toddlers or young children with active EoE complicated by failure to thrive, the elemental diet is generally considered a valid and useful therapeutic option with the highest patient compliance $(12,27)$. In severe disease or when large volumes of the aminoacid-based formula are required to meet the caloric needs and restore the good nutritional status, nasalgastric (NG) or gastric ( $\mathrm{G}$ ) tube feeding is a temporary solution (42). These interventions should be discouraged in the long-term treatment, especially in children with feeding disorders, because they are often fraught with difficult solid food oral reintroduction and progressive feeding skills regression (12). In children with multiple food triggers and subsequent high diet restrictions, elemental formulas can also be used as supplements of protein and energy necessary for adequate growth and puberty spurt (12).

Although the elemental diet can induce a rapid diseaseremission in only 2 weeks, several disadvantages limit its adherence (Table 2) (43). The poor palatability, highly restrictive nature, costs, and psychosocial isolation are the main reasons for treatment discontinuation and low compliance $(12,17,27)$. To remedy these issues, the elemental diet is often modified, introducing one or two less allergenic foods (generally vegetables or fruits) in addition to the aminoacid-based formula $(12,27)$. Moreover, elemental formulas are also available in flavored and unflavored formulations to address patient taste and preferences (12). Pediatric elemental formulas are nutritionally complete but do not contain dietary fiber. Thus, fiber supplements (free of known allergens) should be prescribed in patients who develop or are more prone to constipation (12).

\section{Food Elimination Diets Empirical FED}

In general, more foods are eliminated from the diet, more likely the remission is achieved at the first endoscopy. FED is the most widely used diet treatment for EoE. The first proposed 


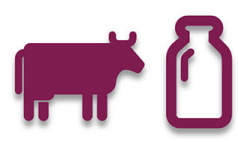

Cow's, goat's, and sheep's milk and milk products (cheese, yogurt, butter, ice creams, milkshakes, custard, crème caramel, rice pudding).

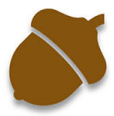

Almond, Brazil nut, beechnut, butternut, cashew, chestnut, coconut, hazelnut, macadamia nut, marzipan natural nut extract, nut butters, nut milk, nut paste, nut pieces, pecan, pesto.

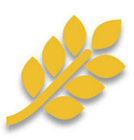

Wheat, wheat-containing foods (bread, toast, biscuits, cookies, donuts, muffins, pretzel, pancakes, waffles, crackers, cream desserts, sweets, candies, pasta, soups, sauces, malted food, breaded or floured vegetables, beer, whiskey).
Egg, egg-containing foods (pasta, cakes, biscuits, cookies, donuts, muffins, pretzel, pancakes, waffles, crackers, cream desserts, sweets, candies, processed meat, goose liver, mayonnaise, breaded vegetables, sauces)

FIGURE 2 | Most allergenic groups of foods that trigger eosinophilic esophagitis.

Fish (salmon, tuna), shellfish (crab, lobster, prawns, shrimps), and mollusks (cockles, mussels, octopus, oyster, snails, squid).
Soy sauce, tofu, edamame, tempeh, vegetarian meat.

\section{ADVANTAGES}

- May lead to early identification of food triggers

- Short diagnostic process

- Avoid unnecessary diet restrictions

\section{DISAVANTAGES}

- Less effective

\section{INDICATIONS}

- Pediatric patients

- Mild-moderate symptoms of long duration

- Non-various diet rich in milk and wheat

\section{ADVANTAGES}

- Efficacy

DISAVANTAGES

- Up to 7 EGDs with single food reintroduction

- High diet restrictions $\rightarrow$ low compliance

- High risk of potential nutritional deficiencies

INDICATIONS

- Adult patients with normal or high BMI

- Significant symptoms (trouble swallowing)

- Baseline diet rich in fruit and vegetable

- Time to cook and financial resources

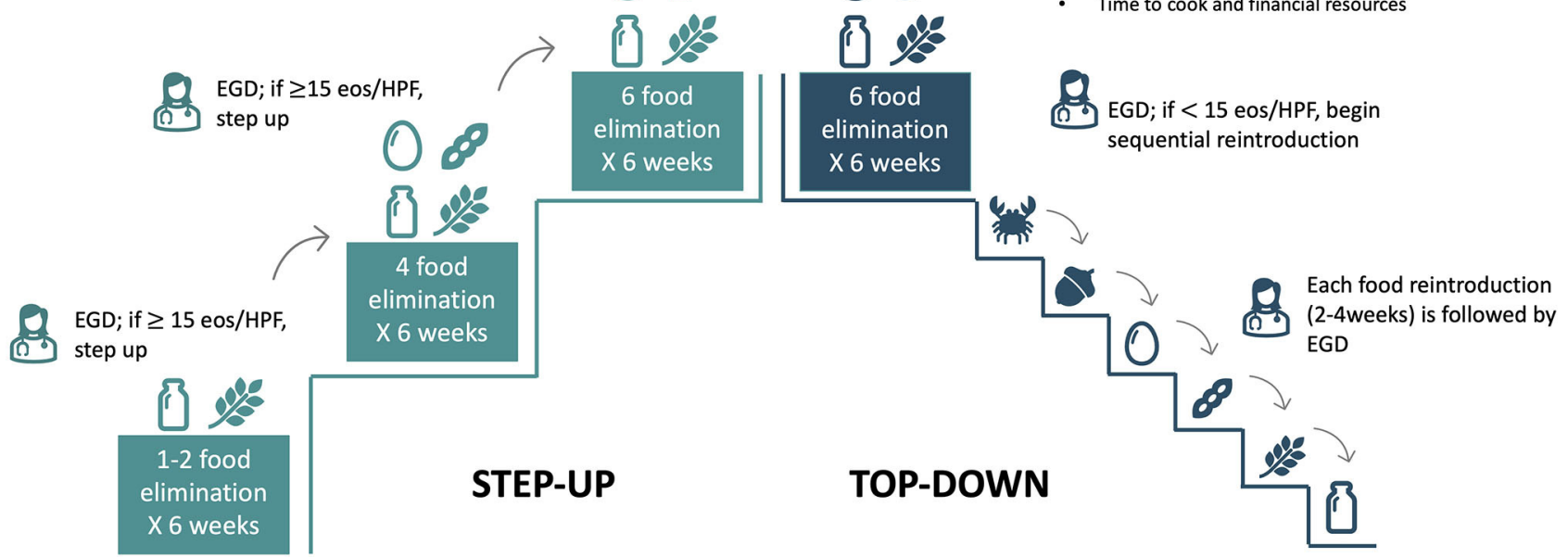

FIGURE 3 | Top-down and step-up approaches: indications, advantages, and disadvantages. EGD, Esophagogastroduodenoscopy.

FED was founded on avoiding the six most common foodtriggers of EoE in the Western diet, such as milk, wheat, egg, soy/legumes, peanut/tree nuts, and seafood/fish (Figure 2) (44). Patients should be advised that all these foods should be avoided both in fresh and backed forms (12). The 6-FED effectively induces histologic remission in about $74 \%$ of children and $70 \%$ of adults with EoE (Table 1) (45). Studies assessing the efficacy of 6-FED have been fundamental to find that the most common food triggers are cow's milk (up to $85 \%$ of the pediatric cases), followed by wheat/gluten (up to 60\%), egg, and soy/legumes 


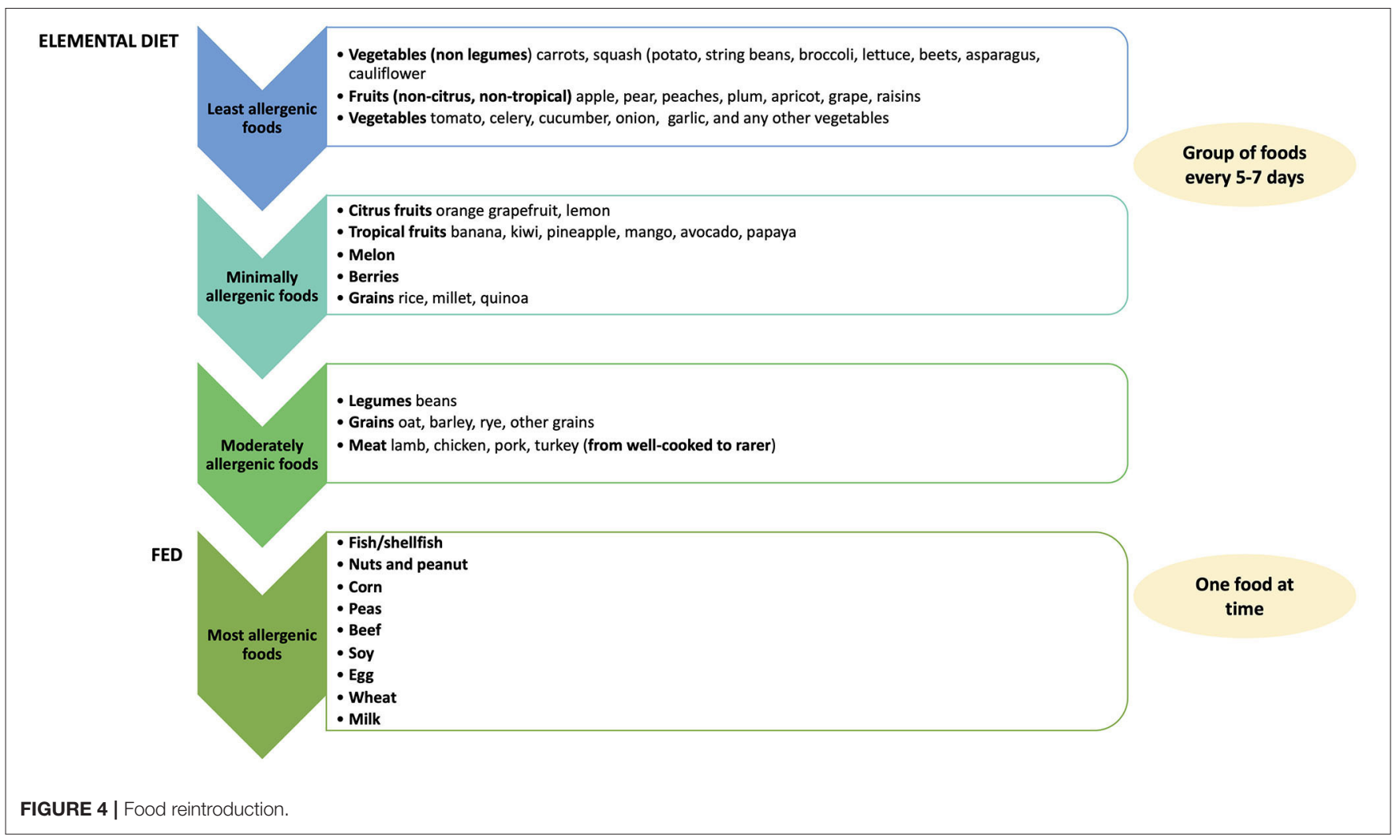

with geographic variations, primarily due to the different food cultures (37). Consequently, nuts and fish/seafood rarely trigger EoE. Therefore, most of the patients who histologically recover with 6-FED were allergic to only 1-3 foods (19).

Although 6-FED is less restrictive than the elemental diet, it still can be challenging to avoid all the six groups of foods. Several drawbacks limit the adherence to 6-FED due to the high level of dietary restriction and the need of frequent upper GI endoscopies to identify the culprit food(s) (12). For these reasons, 6 -FED is generally not considered the ideal therapeutic approach in most EoE patients. Therefore, subsequent studies proposed and assessed the utility of less restrictive FEDs that consisted of avoiding the most common food triggers. 4-FED (milk, wheat, egg, and soy/legumes-free diet) induced histologic remission in 64 and $54 \%$ of children and adults, respectively $(46,47)$. In studies evaluating the efficacy of 4-FED, milk and wheat were the most common triggers of EoE (12). Children and adults avoiding these two foods (2-FED) achieved complete remission in 40 and $44 \%$ of cases, respectively. The elimination of cow's milk (1-FED) demonstrated disease-remission rates of $44-51 \%$ in pediatric patients (27). In a recent systematic review with meta-analysis, the overall efficacy of a milk-free diet was about 70\% (45).

There are two strategies for avoiding foods in FED with different indications, strengths, and weaknesses (Figure 3) (12, 27). FED can be managed with a top-down approach removing milk, wheat, egg, soy/legumes, peanut/tree nuts, and seafood/fish (6-FED) simultaneously. If disease-remission is achieved $(<15$ eos/HPF), the avoided foods can be sequentially added to the patient's diet, with clinical evaluations and esophagealgastroduodenoscopy after each reintroduction, to identify the true allergenic trigger(s) $(12,22)$. Although more effective, this approach is limited by several endoscopic procedures (at least six), high diet restrictions, and potential nutritional deficiencies that may negatively impact patient and family compliance (12, 22). Moreover, a more restrictive diet requires high financial resources and time for buying and preparing alternative meals. For these reasons, the top-down approach is generally indicated in adult patients with severe esophageal symptoms limiting the normal feed (i.e., swallowing issues), adequate/high body mass index (BMI), and without nutritional deficiencies (12). Recently, Molina-Infante et al. tested a prospective step-up approach to empiric food elimination (13). The step-up approach consists of the initial elimination of one (1-FED) or two (2-FED) more common allergenic foods (milk and wheat) (13). If a complete remission is not achieved, diet is further restricted to a 4-FED and eventually to 6-FED (13). Although less effective, this dietary approach leads to faster and earlier identification of food triggers [one to four GI endoscopies to identify food trigger(s)] than the top-down approach, avoiding unnecessary diet restrictions $(12,13,27)$. A step-up approach is generally preferred in children and adolescents with mild-moderate GI symptoms, a diet rich in milk and wheat, and signs of impaired growth or BMI (Figure 3).

\section{Allergy-Test Directed Elimination Diet}

$\mathrm{EoE}$ is a T2 immune-mediated disease, where IgEs do not have a specific pathogenetic role. Based on the results of skin 


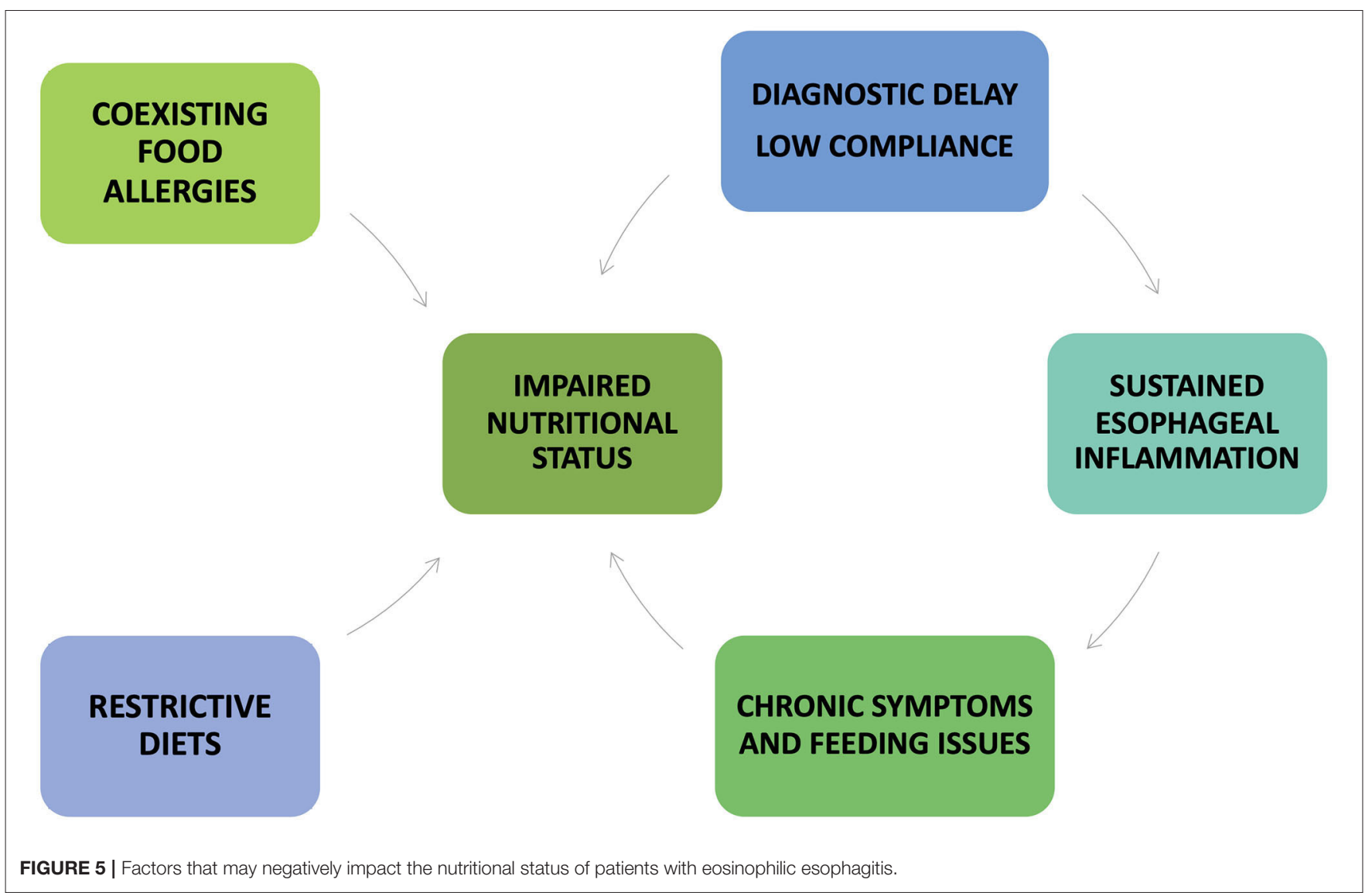

prick tests and atopy patch tests, Spergel et al. reported that about $75 \%$ of children achieved a significant improvement in EoE symptoms and esophageal inflammation (48). However, subsequent studies found that atopy patch tests, skin prick tests, food-specific serum IgEs did not reliably predict food triggers and did not have a clear role in evaluating patients with $\operatorname{EoE}(49,50)$. Moreover, a meta-analysis revealed that this diet approach induces histologic remission in $45.5 \%$ of patients, and efficacy rates were significantly lower in adults than in children (45). According to this evidence, current American and European guidelines do not recommend allergy test-based dietary elimination therapies $(2,28,51)$.

\section{HOW TO MANAGE FOOD REINTRODUCTION AND LONG-TERM TREATMENT?}

When a FED (empirical food elimination or elemental diet) is implemented, the GI endoscopy should be performed after 6-12 weeks to assess the histologic remission $(2,30)$. Once clinical and histologic remission is achieved, a single food or food group is gradually reintroduced based on the specific diet approach. The endoscopy should be made after 4-6 weeks each reintroduction to confirm or exclude disease remission and before proceeding to other food reintroduction $(2,28,43)$. Food reintroduction should start from the less allergenic foods (fruits and vegetables) to the most common food triggers (52). In patients treated with elemental diet or 6-FED, Cianferoni et al. recommended reintroducing the high-risk foods (milk, wheat, soy, and/or egg) one at a time, whereas medium-risk foods (legumes, seafood, nuts) may be re-administered at one time, and low-risk foods (fruit and vegetables) may be reintroduced in groups every 5 7 days (Figure 4) $(12,52)$. If symptoms do not recur after reintroducing 4-5 new foods from one group, endoscopy is performed 1-2 months later (52). On the contrary, if patients become symptomatic or relapse after reintroducing a specific food, that food is definitively excluded from the diet (52).

If EoE children achieve complete disease remission on a freemilk diet (1-FED), cow's milk and milk-containing products (included all mammalian milk and partially and extensively hydrolyzed formulas) should be removed from the diet. However, it is reported that some patients can tolerate baked milk products that may be tried in the diet followed by an upper GI endoscopy. Notably, children sensitized (positive food-specific IgEs or skin test) to previously tolerated foods removed from the diet because of EoE triggers, should be referred to a pediatric allergist before the reintroduction at home (12). As already reported in patients with atopic dermatitis, children with EoE may develop IgE-mediated immediate hypersensitivity to food previously identified as the causative agent for EoE $(53,54)$. 
TABLE 3 | Nutritional assessment [Adapted from Cianferoni et al. (12)].

\begin{tabular}{|c|c|c|}
\hline $\begin{array}{l}\text { Nutritional } \\
\text { assessment }\end{array}$ & Parameters & $\begin{array}{l}\text { Health care } \\
\text { specialist }\end{array}$ \\
\hline Clinical history & $\begin{array}{l}\text { Symptom onset } \\
\text { Food-related symptoms } \\
\text { Extraesophageal manifestations } \\
\text { and comorbidities }\end{array}$ & $\begin{array}{l}\text { Gastroenterologist } \\
\text { Allergist } \\
\text { Pediatrician }\end{array}$ \\
\hline Anthropometric data & $\begin{array}{l}\text { Weight } \\
\text { Height } \\
\text { BMl }\end{array}$ & $\begin{array}{l}\text { Gastroenterologist } \\
\text { Allergist } \\
\text { Pediatrician } \\
\text { Nutritionist }\end{array}$ \\
\hline $\begin{array}{l}\text { Patient diet and } \\
\text { feeding habits }\end{array}$ & $\begin{array}{l}\text { Breakfast, lunch, snacks, dinner } \\
\text { (food diary) } \\
\text { Food variety }\end{array}$ & Nutritionist \\
\hline $\begin{array}{l}\text { Identification of } \\
\text { feeding issues }\end{array}$ & $\begin{array}{l}\text { Description of a typical meal; } \\
\text { food and texture preferences. } \\
\text { Swallowing issues } \\
\text { Delayed onset of oral-motor skills }\end{array}$ & Nutritionist \\
\hline $\begin{array}{l}\text { Identification of eating } \\
\text { disorders, behavioral } \\
\text { issues, and } \\
\text { neurological diseases }\end{array}$ & $\begin{array}{l}\text { Unmotivated weight loss } \\
\text { Nervous anorexia } \\
\text { Anxiety } \\
\text { Depression } \\
\text { Fear of eating in public } \\
\text { Fear of food impaction } \\
\text { Autism spectrum disorders }\end{array}$ & Psychologist \\
\hline $\begin{array}{l}\text { Coexisting allergic } \\
\text { and non-allergic } \\
\text { comorbidities }\end{array}$ & $\begin{array}{l}\text { Gastroesophageal reflux } \\
\text { diseases } \\
\text { Coeliac disease } \\
\text { Inflammatory bowel diseases } \\
\text { Esophageal atresia } \\
\text { lgE and non-IgE mediated food } \\
\text { allergies } \\
\text { Food intolerances } \\
\text { Atopic dermatitis }\end{array}$ & $\begin{array}{l}\text { Gastroenterologist } \\
\text { Allergist } \\
\text { Pediatrician }\end{array}$ \\
\hline $\begin{array}{l}\text { Biochemical } \\
\text { assessment }\end{array}$ & $\begin{array}{l}\text { Complete blood count } \\
\text { Iron status (serum ferritin, iron, } \\
\text { total iron-binding capacity, } \\
\text { hemoglobin) } \\
\text { Bone metabolism (calcium, } \\
\text { phosphate, vitamin D, alkaline } \\
\text { phosphatase) } \\
\text { Micronutrient deficiency (folate, } \\
\text { vitamin B12, zinc, selenium, } \\
\text { electrolytes) } \\
\text { Macronutrient deficiency } \\
\text { (albumin, prealbumin, total } \\
\text { protein, blood urea } \\
\text { nitrogen, creatinine) }\end{array}$ & $\begin{array}{l}\text { Gastroenterologist } \\
\text { Allergist } \\
\text { Pediatrician } \\
\text { Nutritionist }\end{array}$ \\
\hline $\begin{array}{l}\text { Compliance to } \\
\text { therapy }\end{array}$ & $\begin{array}{l}\text { Follow-up EGD with biopsies } \\
\text { Clinical scores }\end{array}$ & $\begin{array}{l}\text { Gastroenterologist } \\
\text { Allergist } \\
\text { Pediatrician }\end{array}$ \\
\hline
\end{tabular}

"No current guidelines exist on DEXA use in patients on a milk-free diet or topical steroid therapy (12).

$B M I$, body mass index; EGD, esophageal-gastroduodenoscopy; lgE, immunoglobulin E.

A significant group ( $\sim 20 \%$ ) of adults and children treated with an elimination diet do not respond to the dietary approach, even after mostly eaten trigger foods are removed, or a more restrictive 6-FED is implemented. In these cases, after assessing the patient's compliance, combination therapy with FED + PPI is generally recommended, or clinicians may add a topical corticosteroid and gradually expand the diet, reintroducing foods (12).
Due to its chronic/remittent nature, EoE requires lifelong therapy $(2,28)$. Patients following a dietary regimen should be widely informed of the need for repeated follow-up endoscopies. Food reintroduction in patients treated with a 6 -FED requires at least six endoscopies and several months to identify the culprit food(s). In children exclusively fed with the aminoacidbased formula, the food-reintroduction process is even longer and loaded by several endoscopies. Once the culprit food(s) is identified, the long-term diet therapy is only based on exclusively avoiding the food(s) responsible for esophageal inflammation (55). In adults, the strict avoidance of trigger food(s) maintains a complete remission (clinical and histologic remission) for up to 3 years $(43,56)$. Notably, the prolonged elimination of a food or a group of trigger foods might induce potential nutritional deficiency.

\section{NUTRITIONAL CONSIDERATIONS AND PATIENT EDUCATION}

Several factors may negatively impact the nutritional status of patients with EoE (Figure 5).

Firstly, children with EoE generally present symptoms that may limit the adequate nutritional intake, such as recurrent vomiting and regurgitation, abdominal pain, lack of appetite, low volume and/or poor variety food intake, grazing, and spitting food out (31). Patients with chronic esophageal inflammation develop compensative feeding habits (i.e., drinking a lot during meals, eating slowly, chewing carefully, cutting food into small pieces, lubricating foods with sauces or liquids), or avoiding some foods (meat, crusty bread, pills) (20). Moreover, young children fed for a long time with liquid formula do not engage masticatory muscles and are at increased risk of delayed onset of oral-motor skills (57).

Secondly, EoE is often delayed or misdiagnosed. It is reported that diagnostic delay mainly occurs in the first two decades of life and is more likely associated with tissue remodeling complications, such as esophageal rings and strictures, and further prolong the GI symptoms and feeding discomfort $(58,59)$.

Although occurring in pediatric patients, esophageal strictures generally complicate the disease course in adulthood since esophageal fibrosis becomes an irreversible process more challenging to treat with available therapies (58). Patients with previous food impaction episodes may have a high risk of developing anxiety and eating disorders, compromising the adequate nutrient intake $(17,60)$. Therefore, chronic GI symptoms, compensative feeding habits, eating disorders may all complicate the nutritional status of EoE patients, especially if they are children.

Thirdly, the coexistence of multiple (IgE and non-IgE mediated) food allergies might be a further reason for failure to thrive and undernutrition. On the other hand, longterm restrictive FEDs may compromise adequate micronutrient intake, although they do not appear to worsen child growth or BMI $(31,61)$. For these reasons, in children treated with 1- or 2-FED, regular clinical follow-up is recommended to identify 
TABLE 4 | Nutritional deficiencies associated with food elimination and appropriate substitutions [Adapted from Bashaw et al. (66)].

\begin{tabular}{|c|c|c|c|c|c|c|}
\hline & Milk & Wheat & Egg & Soy & Nuts & Fish/shellfish \\
\hline \multicolumn{7}{|l|}{ Macronutrient } \\
\hline Protein & $x$ & & $x$ & $x$ & $x$ & $x$ \\
\hline Fiber & & $x$ & & & $x$ & \\
\hline \multicolumn{7}{|l|}{ Micronutrient } \\
\hline Iron & & $x$ & & $x$ & & $x$ \\
\hline Zinc & & $x$ & & $x$ & $x$ & $x$ \\
\hline Copper & & & & & $x$ & $x$ \\
\hline Selenium & & $x$ & $x$ & & $x$ & $x$ \\
\hline Vitamin A & $x$ & & $x$ & & & \\
\hline B5-Pantothenic acid & $x$ & & $x$ & & & \\
\hline B6-Pyridoxine & & $x$ & & $x$ & & \\
\hline B7-Biotin & & $x$ & $x$ & & & \\
\hline B9-Folate & & $x$ & & $x$ & $x$ & \\
\hline B12-Cobalamin & $x$ & & $x$ & & & $x$ \\
\hline lodine & $x$ & & & & & $x$ \\
\hline Substitutions & $\begin{array}{l}\text { Meats, legumes, } \\
\text { whole grains, nuts, } \\
\text { fortified foods, and } \\
\text { beverages }\end{array}$ & $\begin{array}{l}\text { Fortified foods, fruits, } \\
\text { vegetables, other } \\
\text { grains (barley, oat, } \\
\text { rice, corn, rye, millet, } \\
\text { teff, quinoa, } \\
\text { buckwheat, } \\
\text { amaranth) }\end{array}$ & $\begin{array}{l}\text { Meats, legumes, } \\
\text { whole grains } \\
\text { (gluten-free) }\end{array}$ & $\begin{array}{l}\text { Meats, other } \\
\text { legumes, fortified } \\
\text { beverages }\end{array}$ & $\begin{array}{l}\text { Meats, seeds, } \\
\text { legumes }\end{array}$ & $\begin{array}{l}\text { Meats, legumes, } \\
\text { seeds, fortified } \\
\text { beverages }\end{array}$ \\
\hline
\end{tabular}

early potential nutritional deficiency and growth impairment (Table 3).

Finally, the low compliance to therapy is the main reason for therapeutic failure and persistent active inflammation (17).

Nutritionists have a crucial role in evaluating nutritional status (Table 3). A nutritionist should meticulously evaluate the diet of patients (i.e., veggie or lactose-free diets) to determine the degree of exposure to high-risk groups of foods and the potential nutritional and psychological effects of their elimination $(62,63)$. Before beginning a diet therapy and during the follow-up period, clinicians should periodically assess the nutritional status of patients and rule out the potential nutritional deficiency. Then, clinical (symptoms, comorbidities, feeding habits/disorders) and anthropometric data should be collected and carefully evaluated to address the best therapeutic choice.

EoE may appear with failure to thrive, one of the most described complications in young children $(64,65)$. Moreover, the risk of nutritional deficiency and impaired growth also increases with the restrictive nature of the diet and the number of removed foods. Vitamin D deficiency is widespread in Western Countries and is frequently found in patients with chronic inflammatory diseases, including allergic disorders (31). Although published studies are often conflicting, patients with EoE are at high risk of impaired bone metabolism and vitamin
D deficiency due to the intrinsic nature of the esophageal inflammation, long-term treatment with topical corticosteroids, and FED (31). Iron deficiency anemia may be a consequence of selective diets. The fear of new food impaction episodes leads patients to voluntarily remove the culprit food (especially steak). If failure to thrive or nutritional deficiencies are suspected, biochemical tests (i.e., bone and iron metabolism, serum albumin, and prealbumin) should be performed. When a micro- or macronutrient deficiency is confirmed, nutritional supplements should be promptly provided (Table 4) (66).

Another critical point concerns the patient's education. Clinicians should carefully inform patients and their families regarding what they can eat and provide the appropriate (written or online) resources for additional information (12). Moreover, patients should also be advised on the risk of potential allergen contaminations. According to the specific European legislation (https://www.mise.gov.it/index.php/it/impresa/competitivita-enuove-imprese/industria-alimentare/etichettatura-alimentare), clinicians should provide information on packaged foods and educate patients and families to read and correctly interpret the labels of food products. European law established that major food allergens must be declared and reported in the labels of packaged food or available to consumers for non-packaged foods (catering, fresh and cooked foods) (12). Ingredients may change 
over time, and labels of regularly consumed food should be read each time (12). Fourteen significant allergens must be identified and reported in labels: cereals containing gluten (wheat, rye, barley, oats, spelled, and Kamut), crustaceans, eggs, fish, peanut, soy, milk (including lactose), nuts (almonds, Brazil nuts, cashews, hazelnuts, macadamia, pecan nuts, pistachio nuts, and walnuts), celery, mustard, sesame, sulfites, lupin, and mollusks (https://www.mise.gov.it/index.php/it/impresa/competitivita-enuove-imprese/industria-alimentare/etichettatura-alimentare). The precautionary allergen labeling ("may contain") is not mandatory for European law (12). However, the risk of allergen cross-contamination and trace exposure for foods reporting this warning is variable and still not established in EoE patients (12).

\section{HOW TO IMPROVE PATIENT'S COMPLIANCE: THE ROLE OF THE MULTIDISCIPLINARY TEAM}

The chronic nature of EoE, comorbidities, long-term restrictive therapies and strict endoscopic follow-up are the main stressful factors for patients and their families (17). Therefore, it is evident that EoE significantly impacts the QoL of both pediatric and adult patients (17). The complexity and the clinical heterogeneity of this emerging chronic disease implies the need for a multidisciplinary approach, including allergist, pediatrician, gastroenterologist, nutritionist, and psychologist to manage these patients (Table 3) (31). In high specialized Centers, all these specialists should be present during the entire course of the disease and guarantee the transition from the pediatric to the adult setting. Allergists should identify other coexisting atopic comorbidities (eczema, allergic rhinitis, asthma, food/drug allergy, and anaphylaxis) and provide adequate treatment if symptoms are not controlled. Allergy assessment is also fundamental to prevent potential IgE-mediated reactions when foods (especially milk) are reintroduced. Strict clinical and endoscopic follow-up is required to evaluate patient compliance, long-term treatment side effects, and assess disease remission.

\section{REFERENCES}

1. Licari A, Votto M, D'Auria E, Castagnoli R, Caimmi SME, Marseglia GL. Eosinophilic gastrointestinal diseases in children: a practical review. Curr Pediatr Rev. (2020) 16:106-14. doi: 10.2174/1573396315666191022154432

2. Dellon ES, Liacouras CA, Molina-Infante J, Furuta GT, Spergel JM, Zevit $\mathrm{N}$, et al. Updated international consensus diagnostic criteria for eosinophilic esophagitis: proceedings of the AGREE conference. Gastroenterology. (2018) 155:1022-33. doi: 10.1053/j.gastro.2018.07.009

3. Dellon ES, Hirano I. Epidemiology and natural history of eosinophilic esophagitis. Gastroenterology. (2018) 154:31932. doi: 10.1053/j.gastro.2017.06.067

4. Licari A, Votto M, Scudeller L, De Silvestri A, Rebuffi C, Cianferoni A, et al. Epidemiology of nonesophageal eosinophilic gastrointestinal diseases in symptomatic patients: a systematic review and meta-analysis. J Allergy Clin Immunol Pract. (2020) 8:1994-2003. doi: 10.1016/j.jaip.2020.01.060

5. Navarro P, Arias Á, Arias-González L, Laserna-Mendieta EJ, Ruiz-Ponce M, Lucendo AJ. Systematic review with meta-analysis: the growing incidence and prevalence of eosinophilic oesophagitis in children and adults
Notably, children with severe disease, multiple food allergies, non-allergic comorbidities (such as esophageal atresia or genetic disorders) or treated with elimination diets (elemental diets or empirical FEDs) require a regular pediatric evaluation of their growth and nutritional status. Finally, psychological support should be provided when behavioral, mood diseases, or eating disorders are suspected (17).

\section{CONCLUSION}

EoE is an emerging chronic allergic disease with a relevant impact on the health care system and patients' QoL. Although the pathogenesis is not entirely understood, EoE is a T2 inflammatory disease mainly triggered by food allergens. Diet therapy and medications are both first-line treatments. The choice of one or the other therapy depends on the disease phenotypes (allergic vs. non-allergic, inflammatory vs. fibro-stenotic), patient's age (adult vs. childhoodonset), food habits, patient/family preference, and familiar financial resource. Diet therapy is a successful treatment but limited by low patient adherence, the need for several endoscopies, food restriction, psychosocial impacts, and potential nutritional deficiency. All these limitations could be effectively overcome with multidisciplinary and personalized management. Considering the clinical heterogeneity of EoE, future efforts should be addressed to personalize treatments. Multidisciplinary management, a personalized approach, and proactive education on the importance of treatments and regular endoscopic follow-up may be the keys to a more successful therapeutic strategy.

\section{AUTHOR CONTRIBUTIONS}

MV reviewed the literature and wrote the manuscript. MDF reviewed the literature and the manuscript. AL, GLM, ADS, MVL, and CMR revised the manuscript critically for important intellectual content. All authors approved the final version of the manuscript and agreed to be accountable for all aspects of the work. in population-based studies. Aliment Pharmacol Ther. (2019) 49:111625. doi: 10.1111/apt.15231

6. Shaheen NJ, Mukkada V, Eichinger CS, Schofield H, Todorova L, Falk GW. Natural history of eosinophilic esophagitis: a systematic review of epidemiology and disease course. Dis Esophagus. (2018) 31:doy015. doi: 10.1093/dote/doy015

7. Cianferoni A, Jensen E, Davis CM. The role of the environment in eosinophilic esophagitis. $J$ Allergy Clin Immunol Pract. (2021) 9:3268-74. doi: 10.1016/j.jaip.2021. 07.032

8. Votto M, Marseglia GL, De Filippo M, Brambilla I, Caimmi SME, Licari A. early life risk factors in pediatric EoE: could we prevent this modern disease? Front Pediatr. (2020) 8:263. doi: 10.3389/fped.2020.00263

9. Chehade M, Sampson HA, Morotti RA, Magid MS. Esophageal subepithelial fibrosis in children with eosinophilic esophagitis. J Pediatr Gastroenterol Nutr. (2007) 45:319-28. doi: 10.1097/MPG.0b013e31806ab384

10. Simon D, Cianferoni A, Spergel JM, Aceves S, Holbreich M, Venter C, et al. Eosinophilic esophagitis is characterized by a non-IgE-mediated food hypersensitivity. Allergy. (2016) 71:611-20. doi: 10.1111/all.12846 
11. Kagalwalla AF, Shah A, Li BU, Sentongo TA, Ritz S, ManuelRubio $M$, et al. Identification of specific foods responsible for inflammation in children with eosinophilic esophagitis successfully treated with empiric elimination diet. J Pediatr Gastro Nutrition. (2011) 53:145-9. doi: 10.1097/MPG.0b013e31821cf503

12. Cianferoni A, Shuker M, Brown-Whitehorn T, Hunter H, Venter C, Spergel JM. Food avoidance strategies in eosinophilic oesophagitis. Clin Exp Allergy. (2019) 49:269-84. doi: 10.1111/cea.13360

13. Molina-Infante J, Arias Á, Alcedo J, Garcia-Romero R, Casabona-Frances S, Prieto-Garcia A, et al. Step-up empiric elimination diet for pediatric and adult eosinophilic esophagitis: the 2-4-6 study. J Allergy Clin Immunol. (2018) 141:1365-72. doi: 10.1016/j.jaci.2017.08.038

14. Gonsalves N, Yang GY, Doerfler B, Ritz S, Ditto AM, Hirano I. Elimination diet effectively treats eosinophilic esophagitis in adults; food reintroduction identifies causative factors. Gastroenterology. (2012) 142:14519. doi: 10.1053/j.gastro.2012.03.001

15. Votto M, De Filippo M, Caminiti L, Carella F, de Castro G, Landi $M$, et al. Eosinophilic gastrointestinal disorders and allergen immunotherapy: Lights and shadows. Pediatr Allergy Immunol. (2021) 32:814-23. doi: 10.1111/pai.13458

16. Ruffner MA, Cianferoni A. Phenotypes and endotypes in eosinophilic esophagitis. Ann Allergy Asthma Immunol. (2020) 124:233-9. doi: 10.1016/j.anai.2019.12.011

17. Votto M, Castagnoli R, De Filippo M, Brambilla I, Cuppari C, Marseglia GL, et al. Behavioral issues and quality of life in children with eosinophilic esophagitis. Minerva Pediatr. (2020) 72:424-32. doi: 10.23736/S0026-4946.20.05913-7

18. Hirano I, Sharaf R, Stollman N, Wang K, Falck-Ytter Y, Chan E, et al. Spotlight: treatment of eosinophilic esophagitis (EoE). Gastroenterology. (2020) 158:1788. doi: 10.1053/j.gastro.2020.03.069

19. Steinbach EC, Hernandez M, Dellon ES. Eosinophilic esophagitis and the eosinophilic gastrointestinal diseases: approach to diagnosis and management. J Allergy Clin Immunol Pract. (2018) 6:1483-95. doi: 10.1016/j.jaip.2018.06.012

20. Muir AB, Brown-Whitehorn T, Godwin B, Cianferoni A. Eosinophilic esophagitis: early diagnosis is the key. Clin Exp Gastroenterol. (2019) 12:3919. doi: 10.2147/CEG.S175061

21. Shoda T, Wen T, Aceves SS, Abonia JP, Atkins D, Bonis PA, et al. Eosinophilic oesophagitis endotype classification by molecular, clinical, and histopathological analyses: a cross-sectional study. Lancet Gastroenterol Hepatol. (2018) 3:477-88. doi: 10.1016/S2468-1253(18)30096-7

22. Keely S, Talley NJ. Endophenotyping eosinophilic oesophagitis: a new era for management? Lancet Gastroenterol Hepatol. (2018) 3:449-50. doi: 10.1016/S2468-1253(18)30134-1

23. Lucendo AJ, Arias Á, González-Cervera J, Yagüe-Compadre JL, Guagnozzi D, Angueira T, et al. Empiric 6-food elimination diet induced and maintained prolonged remission in patients with adult eosinophilic esophagitis: a prospective study on the food cause of the disease. J Allergy Clin Immunol. (2013) 131:797-804. doi: 10.1016/j.jaci.2012.12.664

24. Constantine G, Seth N, Chokshi N, Minard CG, Guffey D, Olive AP, et al. Combination steroid and test-based food elimination for eosinophilic esophagitis: a retrospective analysis. J Pediatr Gastroenterol Nutr. (2017) 64:933-8. doi: 10.1097/MPG.0000000000001584

25. Licari A, Castagnoli R, Marseglia A, Olivero F, Votto M, Ciprandi G, et al. Dupilumab to treat type 2 inflammatory diseases in children and adolescents. Paediatr Drugs. (2020) 22:295-310. doi: 10.1007/s40272-020-0 0387-2

26. Lucendo AJ, Arias Á, Molina-Infante J. Efficacy of proton pump inhibitor drugs for inducing clinical and histologic remission in patients with symptomatic esophageal eosinophilia: a systematic review and metaanalysis. Clin Gastroenterol Hepatol. (2016) 14:13-22. doi: 10.1016/j.cgh.2015. 07.041

27. Chehade M, Aceves SS. Treatment of eosinophilic esophagitis: diet or medication? J Allergy Clin Immunol Pract. (2021) 9:3249-56. doi: 10.1016/j.jaip.2021.07.029

28. Lucendo AJ, Molina-Infante J, Arias Á, von Arnim U, Bredenoord AJ, Bussmann C, et al. Guidelines on eosinophilic esophagitis: evidencebased statements and recommendations for diagnosis and management in children and adults. United European Gastroenterol J. (2017) 5:33558. doi: 10.1177/2050640616689525

29. Kelly KJ, Lazenby AJ, Rowe PC, Yardley JH, Perman JA, Sampson HA. Eosinophilic esophagitis attributed to gastroesophageal reflux: improvement with an amino acid-based formula. Gastroenterology. (1995) 109:150312. doi: 10.1016/0016-5085(95)90637-1

30. Asher Wolf W, Huang KZ, Durban R, Iqbal ZJ, Robey BS, Khalid FJ, et al. The six-food elimination diet for eosinophilic esophagitis increases grocery shopping cost and complexity. Dysphagia. (2016) 31:76570. doi: 10.1007/s00455-016-9739-1

31. Votto M, De Filippo M, Olivero F, Raffaele A, Cereda E, De Amici M, et al. Malnutrition in eosinophilic gastrointestinal disorders. Nutrients. (2020) 13:128. doi: 10.3390/nu13010128

32. Chehade M, Brown S. Elimination diets for eosinophilic esophagitis: making the best choice. Expert Rev Clin Immunol. (2020) 16:67987. doi: 10.1080/1744666X.2020.1801419

33. Votto M, Raffaele A, De Filippo M, Caimmi S, Brunero M, Riccipetitoni $\mathrm{G}$, et al. Eosinophilic gastrointestinal disorders in children and adolescents: a single-center experience. Dig Liver Dis. (2021) 14:S1590-8658(21)003418. doi: 10.1016/j.dld.2021.06.027

34. Capucilli P, Cianferoni A, Grundmeier RW, Spergel JM. Comparison of comorbid diagnoses in children with and without eosinophilic esophagitis in a large population. Ann Allergy Asthma Immunol. (2018) 121:7116. doi: 10.1016/j.anai.2018.08.022

35. Capucilli P, Hill DA. Allergic comorbidity in eosinophilic esophagitis: mechanistic relevance and clinical implications. Clin Rev Allergy Immunol. (2019) 57:111-27. doi: 10.1007/s12016-019-08733-0

36. De Bortoli N, Penagini R, Savarino E, Marchi S. Eosinophilic esophagitis: update in diagnosis and management. Position paper by the Italian Society of Gastroenterology and Gastrointestinal Endoscopy (SIGE). Dig Liver Dis. (2017) 49:254-60. doi: 10.1016/j.dld.2016.11.012

37. Molina-Infante J, Lucendo AJ. Dietary therapy for eosinophilic esophagitis. $J$ Allergy Clin Immunol. (2018) 142:41-7. doi: 10.1016/j.jaci.2018.02.028

38. Henderson CJ, Abonia JP, King EC, Putnam PE, Collins MH, Franciosi JP, et al. Comparative dietary therapy effectiveness in remission of pediatric eosinophilic esophagitis. J Allergy Clin Immunol. (2012) 129:15708. doi: 10.1016/j.jaci.2012.03.023

39. Markowitz JE, Spergel JM, Ruchelli E, Liacouras CA. Elemental diet is an effective treatment for eosinophilic esophagitis in children and adolescents. Am J Gastroenterol. (2003) 98:777-82. doi: 10.1111/j.1572-0241.2003.07390.x

40. Warners MJ, Vlieg-Boerstra BJ, Verheij J, van Rhijn BD, Van Ampting MT Harthoorn LF, et al. Elemental diet decreases inflammation and improves symptoms in adult eosinophilic oesophagitis patients. Aliment Pharmacol Ther. (2017) 45:777-87. doi: 10.1111/apt.13953

41. Peterson KA, Byrne KR, Vinson LA, Ying J, Boynton KK, Fang JC, et al. Elemental diet induces histologic response in adult eosinophilic esophagitis. Am J Gastroenterol. (2013) 108:759-66. doi: 10.1038/ajg.2012.468

42. Liacouras CA, Spergel JM, Ruchelli E, Verma R, Mascarenhas M, Semeao E, et al. Eosinophilic esophagitis: a 10-year experience in 381 children. Clin Gastroenterol Hepatol. (2005) 3:1198206. doi: 10.1016/S1542-3565(05)00885-2

43. Visaggi P, Mariani L, Pardi V, Rosi EM, Pugno C, Bellini M, et al. Dietary management of eosinophilic esophagitis: tailoring the approach. Nutrients. (2021) 13:1630. doi: 10.3390/nu13051630

44. Kagalwalla AF, Sentongo TA, Ritz S, Hess T, Nelson SP, Emerick KM, et al. Effect of six-food elimination diet on clinical and histologic outcomes in eosinophilic esophagitis. Clin Gastroenterol Hepatol. (2006) 4:1097102. doi: 10.1016/j.cgh.2006.05.026

45. Arias A, González-Cervera J, Tenias JM, Lucendo AJ. Efficacy of dietary interventions for inducing histologic remission in patients with eosinophilic esophagitis: a systematic review and meta-analysis. Gastroenterology. (2014) 146:1639-48. doi: 10.1053/j.gastro.2014.02.006

46. Kagalwalla AF, Wechsler JB, Amsden K, Schwartz S, Makhija M, Olive A, et al. Efficacy of a 4-food elimination diet for children with eosinophilic esophagitis. Clin Gastroenterol Hepatol. (2017) 15:1698707. doi: 10.1016/j.cgh.2017.05.048

47. Molina-Infante J, Arias A, Barrio J, Rodríguez-Sánchez J, Sanchez-Cazalilla M, Lucendo AJ. Four-food group elimination diet for adult eosinophilic 
esophagitis: a prospective multicenter study. J Allergy Clin Immunol. (2014) 134:1093-9. doi: 10.1016/j.jaci.2014.07.023

48. Spergel JM, Andrews T, Brown-Whitehorn TF, Beausoleil JL, Liacouras CA. Treatment of eosinophilic esophagitis with specific food elimination diet directed by a combination of skin prick and patch tests. Ann Allergy Asthma Immunol. (2005) 95:336-43. doi: 10.1016/S1081-1206(10)61151-9

49. Molina-Infante J, Martin-Noguerol E, Alvarado-Arenas M, Porcel-Carreño SL, Jimenez-Timon S, Hernandez-Arbeiza FJ. Selective elimination diet based on skin testing has suboptimal efficacy for adult eosinophilic esophagitis. $J$ Allergy Clin Immunol. (2012) 130:1200-2. doi: 10.1016/j.jaci.2012.06.027

50. Philpott H, Nandurkar S, Royce SG, Thien F, Gibson PR. Allergy tests do not predict food triggers in adult patients with eosinophilic oesophagitis. A comprehensive prospective study using five modalities. Aliment Pharmacol Ther. (2016) 44:223-33. doi: 10.1111/apt.13676

51. Hirano I, Chan ES, Rank MA, Sharaf RN, Stollman NH, Stukus DR, et al. AGA institute and the joint task force on allergy-immunology practice parameters clinical guidelines for the management of eosinophilic esophagitis. Gastroenterology. (2020) 158:1776-86. doi: 10.1053/j.gastro.2020.02.038

52. Spergel JM, Shuker M. Nutritional management of eosinophilic esophagitis. Gastrointest Endosc Clin N Am. (2008) 18:17994. doi: 10.1016/j.giec.2007.09.008

53. Hill DA, Shuker M, Cianferoni A, Wong T, Ruchelli E, Spergel JM, et al. The development of IgE-mediated immediate hypersensitivity after the diagnosis of eosinophilic esophagitis to the same food. J Allergy Clin Immunol Pract. (2015) 3:123-4. doi: 10.1016/j.jaip.2014.08.005

54. Chang A, Robison R, Cai M, Singh AM. Natural history of food-triggered atopic dermatitis and development of immediate reactions in children. $J$ Allergy Clin Immunol Pract. (2016) 4:229-36. doi: 10.1016/j.jaip.2015.08.006

55. Lucendo AJ. Meta-analysis-based guidance for dietary management in eosinophilic esophagitis. Curr Gastroenterol Rep. (2015) 17:464. doi: 10.1007/s11894-015-0464-y

56. Reed CC, Fan C, Koutlas NT, Shaheen NJ, Dellon ES. Food elimination diets are effective for long-term treatment of adults with eosinophilic oesophagitis. Aliment Pharmacol Ther. (2017) 46:836-44. doi: 10.1111/apt.14290

57. Delaney AL, Arvedson JC. Development of swallowing and feeding: prenatal through first year of life. Dev Disabil Res Rev. (2008) 14:10517. doi: $10.1002 /$ ddrr. 16

58. Schoepfer AM, Safroneeva E, Bussmann C, Kuchen T, Portmann S, Simon $\mathrm{HU}$, et al. Delay in diagnosis of eosinophilic esophagitis increases risk for stricture formation in a time-dependent manner. Gastroenterology. (2013) 145:1230-6. doi: 10.1053/j.gastro.2013.08.015

59. Lenti MV, Savarino E, Mauro A, Penagini R, Racca F, Ghisa M, et al. Diagnostic delay and misdiagnosis in eosinophilic oesophagitis. Dig Liver Dis. (2021) 53:1632-39. doi: 10.1016/j.dld.2021.05.017
60. Mehta H, Groetch M, Wang J. Growth and nutritional concerns in children with food allergy. Curr Opin Allergy Clin Immunol. (2013) 13:2759. doi: 10.1097/ACI.0b013e328360949d

61. Colson D, Kalach N, Soulaines P, Vannerom Y, Campeotto F, Talbotec C, et al. The impact of dietary therapy on clinical and biologic parameters of pediatric patients with eosinophilic esophagitis. J Allergy Clin Immunol Pract. (2014) 2:587-93. doi: 10.1016/j.jaip.2014.05.012

62. Mehta P, Furuta GT, Brennan T, Henry ML, Maune NC, Sundaram SS, et al. Nutritional state and feeding behaviors of children with eosinophilic esophagitis and gastroesophageal reflux disease. $J$ Pediatr Gastroenterol Nutr. (2018) 66:603-8. doi: 10.1097/MPG.0000000000 001741

63. Groetch M, Venter C, Skypala I, Vlieg-Boerstra B, Grimshaw K, Durban $\mathrm{R}$, et al. Dietary therapy and nutrition management of eosinophilic esophagitis: a work group report of the american academy of allergy, asthma, and immunology. J Allergy Clin Immunol Pract. (2017) 5:31224. doi: $10.1016 /$ j.jaip.2016.12.026

64. Furuta GT, Katzka DA. Eosinophilic esophagitis. N Engl J Med. (2015) 373:1640-8. doi: 10.1056/NEJMra1502863

65. Liacouras CA, Spergel J, Gober LM. Eosinophilic esophagitis: clinical presentation in children. Gastroenterol Clin North Am. (2014) 43:21929. doi: 10.1016/j.gtc.2014.02.012

66. Bashaw H, Schwartz S, Kagalwalla AF, Wechsler JB. Tutorial: nutrition therapy in eosinophilic esophagitis-outcomes and deficiencies. JPEN J Parenter Enteral Nutr. (2020) 44:600-9. doi: 10.1002/jpen.1738

Conflict of Interest: The authors declare that the research was conducted in the absence of any commercial or financial relationships that could be construed as a potential conflict of interest.

Publisher's Note: All claims expressed in this article are solely those of the authors and do not necessarily represent those of their affiliated organizations, or those of the publisher, the editors and the reviewers. Any product that may be evaluated in this article, or claim that may be made by its manufacturer, is not guaranteed or endorsed by the publisher.

Copyright (c) 2022 Votto, De Filippo, Lenti, Rossi, Di Sabatino, Marseglia and Licari. This is an open-access article distributed under the terms of the Creative Commons Attribution License (CC BY). The use, distribution or reproduction in other forums is permitted, provided the original author(s) and the copyright owner $(s)$ are credited and that the original publication in this journal is cited, in accordance with accepted academic practice. No use, distribution or reproduction is permitted which does not comply with these terms. 